\title{
A Viable New Strategy for the Discovery of Peptide Proteolytic Cleavage Products in Plant-Microbe Interactions
}

\author{
Manuel I. Villalobos Solis, ${ }^{1,2}$ Suresh Poudel, ${ }^{1}$ Clemence Bonnot ${ }^{3}$ Him K. Shrestha, ${ }^{1,2}$ Robert L. Hettich, \\ Claire Veneault-Fourrey, ${ }^{3}$ Francis Martin ${ }^{3}$ and Paul E. Abraham ${ }^{1, \dagger}$ \\ ${ }^{1}$ Chemical Sciences Division, Oak Ridge National Laboratory, Oak Ridge, TN 37831, U.S.A. \\ ${ }^{2}$ Department of Genome Science and Technology, University of Tennessee-Knoxville, Knoxville, TN 37996, U.S.A. \\ ${ }^{3}$ UMR 1136 INRA-Université de Lorraine 'Interactions Arbres/Microorganismes', Laboratoire d'Excellence ARBRE, Centre \\ INRA-Lorraine, 54280 Champenoux, France
}

Accepted 25 June 2020.

Small peptides that are proteolytic cleavage products (PCPs) of less than 100 amino acids are emerging as key signaling molecules that mediate cell-to-cell communication and biological processes that occur between and within plants, fungi, and bacteria. Yet, the discovery and characterization of these molecules is largely overlooked. Today, selective enrichment and subsequent characterization by mass spectrometry-based sequencing offers the greatest potential for their comprehensive characterization, however qualitative and quantitative performance metrics are rarely captured. Herein, we addressed this need by benchmarking the performance of an enrichment strategy, optimized specifically for small PCPs, using state-of-the-art de novo-assisted peptide sequencing. As a case study, we implemented this approach to identify PCPs from different root and foliar tissues of the hybrid poplar Populus $\times$ canescens $717-1 B 4$ in interaction with the ectomycorrhizal basidiomycete Laccaria bicolor. In total, we identified 1,660 and 2,870 Populus and L. bicolor unique PCPs,

Manuel I. Villalobos Solis and Suresh Poudel contributed equally.

${ }^{\dagger}$ Corresponding author: P. E. Abraham; abrahampe@ornl.gov

Funding: This work was supported by the Plant-Microbe Interfaces Science Focus Area supported by the U.S. Department of Energy (DOE) and the Office of Biological and Environmental Research (OBER). The manuscript has been authored by UT-Battelle, LLC, under contract no. DE-AC05-00OR22725 with the U.S. Department of Energy. This work has been partly funded by the Laboratory of Excellence ARBRE (ANR-11LABX-0002-01).

*The $e$-Xtra logo stands for "electronic extra" and indicates there are supplementary materials published online.

The author(s) declare no conflict of interest.

Modified: 9 Nov 2021.

This manuscript has been authored by UT-Battelle, LLC under Contract No. DE-AC05-00OR22725 with the U.S. Department of Energy. The United States Government retains and the publisher, by accepting the article for publication, acknowledges that the United States Government retains a non-exclusive, paid-up, irrevocable, world-wide license to publish or reproduce the published form of this manuscript, or allow others to do so, for United States Government purposes. The Department of Energy will provide public access to these results of federally sponsored research in accordance with the DOE Public Access Plan. respectively. Qualitative results supported the identification of well-known PCPs, like the mature form of the photosystem II complex 5-kDa protein (approximately $3 \mathrm{kDa}$ ). A total of 157 PCPs were determined to be significantly more abundant in root tips with established ectomycorrhiza when compared with root tips without established ectomycorrhiza and extramatrical mycelium of $L$. bicolor. These PCPs mapped to 64 Populus proteins and $69 \mathrm{~L}$. bicolor proteins in our database, with several of them previously implicated in biologically relevant associations between plant and fungus.

Key words: de novo peptide sequencing, liquid chromatography, small peptides, tandem mass spectrometry

The plant peptidome encompasses a mixed array of lowmolecular weight peptides $(<10 \mathrm{kDa})$ or proteolytic cleavage products (PCPs) that are derived from endogenous cellular mechanisms of proteolysis acting in protein turnover (Schaller 2004) or in the maturation of large protein precursors (Farrokhi et al. 2008; Fesenko et al. 2015). PCPs from protein turnover processes may not have pronounced cellular effects in plants but may act as sources or reservoirs of nitrogen (Chen et al. 2002; Huffaker 1990; Müntz 1996; Müntz et al. 2001). By contrast, the group of PCPs derived from protein maturation processes have key roles in plant growth and development, reproduction, and stress responses (Chen et al. 2020; Farrokhi et al. 2008; Tavormina et al. 2015). These types of bioactive PCPs include well-studied families of plant peptide hormones that are classified according to primary sequence characteristics (Tavormina et al. 2015).

Plant PCPs also fulfill diverse roles in the different types of symbiotic interactions with microorganisms in the environment (Plett and Martin 2018). Although PCPs that are the products of protein turnover events have not been directly implicated in biological functions during symbioses, it is interesting to note that the machinery behind protein degradation appears to be affected in plants undergoing symbiotic relationships with microbes, in which the process is deemed essential for cellular maintenance (Song et al. 2015; Szuba et al. 2019; Takeda et al. 2009). Regarding bioactive PCPs, several of them have been characterized as molecular intermediaries in the responses that plants induce on associated microbiota (Farkas et al. 2014; Mergaert et al. 2003; Stec 2006; van Loon et al. 2006). Among 
the different microbial signals that a plant perceives, microbial bioactive PCPs have been shown to alter their hosts cellular behavior in order to survive (Mitchum et al. 2012; Miyawaki et al. 2013; Pellegrin et al. 2019; Plett et al. 2011).

The discovery and characterization of PCPs in plants and in plant-microbe interactions have been expedited with the application of experimental mass spectrometry (MS) methodologies that have used biomaterial known to be enriched in selective families of PCPs or genetically altered to overexpress them, followed by purification or enrichment strategies, and, in some cases mapping the acquired MS data to custom-made databases containing either known PCP precursors, alternate sequence versions of bioactive PCPs, or both (Amano et al. 2007; Durgo et al. 2015; Fesenko et al. 2015; Kondo et al. 2006; Matsuzaki et al. 2010; Mohd-Radzman et al. 2015; Ohyama et al. 2009; Patel et al. 2018; Shinohara and Matsubayashi 2013; Van de Velde et al. 2010; Whitford et al. 2012; Zhang et al. 2006).

All these studies have demonstrated the advantage of MS methodologies for the large-scale identification of PCPs in plants and plant-microbial interactions; however, they have also highlighted several technological challenges associated with their application including the relatively natural low abundance of PCPs as well as undefined proteolytic processing and unusual posttranslational modifications that are normal sequence features on them. Furthermore, several of these studies were also tailored specifically for the detection of known PCP families. Thus, alternative MS approaches that can provide a wider image of known and unknown PCPs involved not only in plants but in plant-microbe interactions are needed.

One of such alternatives is to explore the capabilities of searching MS data with de novo-assisted database searches (Muth et al. 2018). In this approach, peptide sequence tags derived directly from a tandem MS (MS/MS) spectrum are used to better select candidate peptides in a database (Dong et al. 2014; Zhang et al. 2012). In this way, de novo-assisted peptide sequencing facilitates the discovery of new PCPs with unknown origins while circumventing the low sensitivity and impractical implementation of conventional database search algorithms permitting nonspecific cleavage rules (Dong et al. 2014; Kapp et al. 2005).

Combined with experimental practices that enrich peptides $<10 \mathrm{kDa}$ in samples from tissues and cells (Cassidy et al. 2016; Kawashima et al. 2010; Kay et al. 2008; MohdRadzman et al. 2015; Ohyama et al. 2008, 2009; Slavoff et al. 2013), peptide sequencing via de novo-assisted database searches could provide a feasible way to comprehensively detect endogenous groups of PCPs produced in tissues of plants and in cells of microbes undergoing symbiosis. In this study, we thus explored the feasibility of the application of 10-kDa molecular weight cut-off (MWCO) filters to enrich PCPs in biomaterial directly extracted from Populus $\times$ canescens $(P$. tremula $\times P$. alba) plants grown in vitro with the ectomycorrhizal basidiomycete Laccaria bicolor. Interestingly, recent publications on the symbiosis between Populus trees and L. bicolor have shown that the establishment and regulation of this interaction is driven by proteolytically processed mature versions of protein precursors (Plett et al. 2017; Vincent et al. 2012); however, the comprehensive profiling of all types of PCPs expressed in active ectomycorrhizal Populus roots is still missing in literature.

Qualitatively our methodology was able to identify matured and presumably functional PCPs that have been previously characterized in other biological systems as well as providing evidence for PCPs that we posit are the result of uncharacterized protein maturation processes. Quantitatively, a differential PCP abundance analysis determined a total of 157 PCPs that were significantly more abundant in root tips with established ectomycorrhiza (ECM) when compared with root tips without established symbiosis or extramatrical mycelium of L. bicolor, thus suggesting roles in the mutualistic interactions between both organisms. Of these, 96 PCPs mapped to 69 L. bicolor proteins, 56 PCPs mapped to 64 Populus proteins, and five PCPs were shared between 12 Populus and six L. bicolor proteins, respectively. These findings demonstrate that global profiling of PCPs via liquid chromatography (LC)-MS/MS with a de novo-assisted database search could significantly advance the comprehensive understanding of the role of these molecules in plantmicrobe interactions and highlight the general applicability of this experimental strategy to acquire direct evidence of PCPs for complex biological systems.

\section{RESULTS AND DISCUSSION}

\section{Benchmarking the identification and quantitation of peptides from a 10-kDa MWCO filter.}

The low nanomolar to mid-picomolar concentrations to which bioactive PCPs are thought to be active and which experimental measurements in plant tissue cultures have found (MohdRadzman et al. 2015; Narváez-Vásquez et al. 2005) prompted us to evaluate the quantitative accuracy and reproducibility of recovering peptides of less than 100 amino acids by implementing a molecular weight-spin column enrichment strategy. For this purpose, we created a standard benchmarking sample that contained invariable amounts of proteolytically digested universal proteomics standard (UPS1, with 48 proteins, 5 pmol each), combined with invariable amounts of an Escherichia coli crude protein extract to best mimic small endogenous peptides at relatively low abundances within a complex proteome background. In addition, equimolar solutions of 17 heavy AQUA synthetic peptide (Supplementary Table S1) standards in different molar amounts (injection volumes equivalent to $12,25,50,75$, or $100 \mathrm{fmol}$ of each standard) were also spiked into the mix of $E$. coli proteins and UPS1 peptides (Fig. 1) for quantitative benchmarking.

The UPS1 peptides and AQUA standards were identified by de novo peptide sequencing using PEAKS. The PEAKS software is recognized as a standard for automated peptide de novo sequencing, which also introduced the capability of incorporating de novo results into its database search algorithm to improve the sensitivity and accuracy of the identifications (Zhang et al. 2012). Overall, the de novo-assisted database peptide sequencing reliably identified a similar number of peptide-spectrum matches (PSMs) across the experimental benchmark dataset (Fig. 2A) and identified over $55 \%$ of the UPS1 proteins in each sample (Fig. 2B), despite the E. coli crude lysate representing approximately 99\% of the collected peptide biomass during enrichment (based on bicinchoninic acid assay). In addition, all 17 of the AQUA peptides spiked into samples were identified. The calculated peak area for each AQUA peptide provided by PEAKS was also compared with manually curated data obtained with Skyline, which is another popular software that provides an alternative to extract MS1-level abundances of a relatively low number of peptides (Schilling et al. 2012). In this way, we evaluated PEAKS capabilities of providing quantitative values that could be used for relative quantification of novel PCPs identified in complex proteomes.

As observed in Figure 2C, for the spiked AQUA peptide standards, excellent agreement between the Skyline MS1 extracted areas under the curve (AUCs) and PEAKS AUCs were observed $\left(R^{2}>0.98\right)$. In terms of individual peptide responses (Fig. 2D), the lowest $R^{2}$ value observed was for peptide ADESAYLDEWNLTPAAK $\left(R^{2}=0.808\right)$, while the best linear 
response at increasing amounts of injected standards was that from peptide EFDLNFIDK $\left(R^{2}=0.936\right)$. Overall, the measured changes in linear responses demonstrated the ability to accurately recover peptide quantitative information from low relative amounts in a complex proteome background after filtration through a $10-\mathrm{kDa}$ membrane cut-off filter, data acquisition via state-of-the-art MS/MS, and postprocessing using PEAKS.

Qualitative identification metrics of PCPs from the Populus hybrid and its ectomycorrhizal symbiont $L$. bicolor.

After observing high reproducibility and accurate quantitative recovery of peptides, the 10-kDa enrichment strategy and de novo sequencing-assisted database searching was applied to a diverse set of Populus extracts (i.e., xylem sap, roots, and leaves) with or without established L. bicolor ECM as well as extramatrical $L$. bicolor mycelium (Lb EXM), which is defined as the network of hyphae emanating from the ectomycorrhizal tips to the growth medium (Fig. 3A).

At a false discovery rate (FDR) of $<1 \%$ at the peptide level, the sample types varied in the total numbers of identified PCPs as well as their similarity to each other (Fig. 3B, horizontal bars in
UpSet plot). Overall, the measured PCPs had similar peptide lengths (median length of 21 amino acids) and number of basic residues (average of 1) (Supplementary Fig. S1) as compared with what is generally reported in conventional peptide sequencing studies, and this observation can be largely explained by the physiochemical properties favored by the applied electrospray and detection strategies (Jarnuczak et al. 2016).

Across all datasets, 4,564 PCPs were identified, from which 1,653 and 2,859 mapped exclusively to, respectively, Populus and L. bicolor proteins, while 52 PCPs were shared among a number of proteins highly conserved between both organisms, such as elongation factors and histones (Supplementary Table S2, PCPs and proteins information).

Among all sample types, the highest numbers of unique PCPs were detected in Lb EXM and ectomycorrhizal roots (Fig. 3B, vertical bars in UpSet plot). PCP identifications detected across multiple samples were also observed. The datasets with the greatest number of overlapping PCPs were those of leaves of plants with and without ECM, which is to be expected, given the ECM interaction largely affects roots tissues. Additionally, we noticed a significant number of PCPs in common between the Lb EXM samples and the root samples with and without ECM.

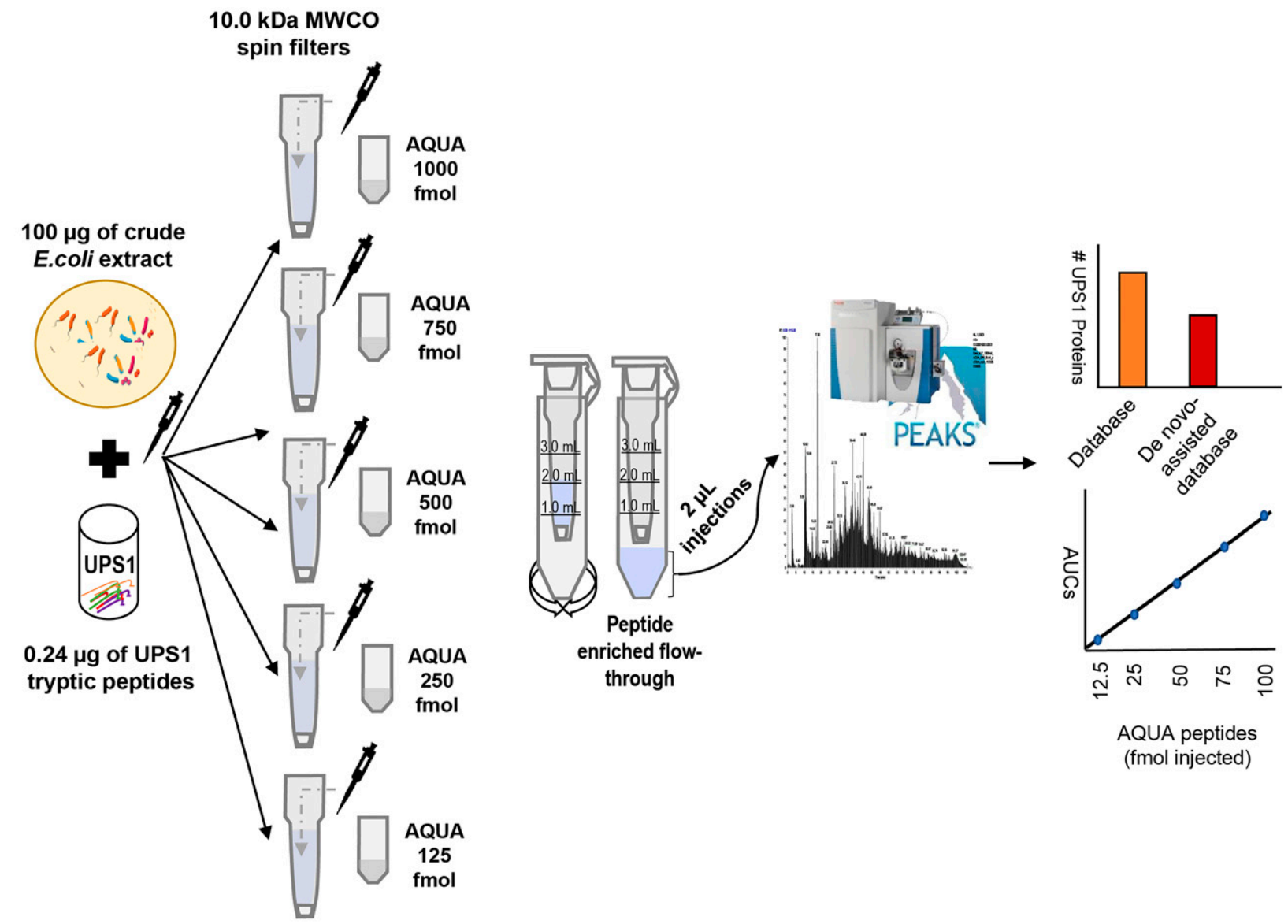

\section{A Benchmark sample set}

\section{B LC-MS/MS measurements}

C Data analysis

Fig. 1. Computational and experimental strategies followed for the identification and quantification of proteolytic cleavage products. A, Samples consisting of $0.24 \mu \mathrm{g}$ of tryptic-digested universal proteomics standard (UPS), $100 \mu \mathrm{g}$ of Escherichia coli protein and different femtomolar amounts of heavy labeled AQUA peptides were prepared in triplicates on top of $10-\mathrm{kDa}$ spin filters. $\mathrm{MWCO}=$ molecular weight cut-off. $\mathbf{B}$, After centrifugation, the flow-throughs were collected and $2 \mu \mathrm{l}$ of each sample were analyzed via liquid chromatography-tandem mass spectrometry (MS/MS), using a Q-Exactive Plus instrument (experimental replicates $n=3$ ). C, UPS1 and AQUA peptides were identified by PEAKS de novo sequencing of MS/MS spectral data. The number of UPS peptide-spectrum matches and proteins were compared with values obtained by the de novo-assisted database search strategy performed with PEAKS. In addition, MS1 peak areas of the spiked AQUA standards were compared with values obtained with Skyline. AUCs = areas under the curve. 
Previous reports have demonstrated that bioactive PCPs can be occupied by posttranslational chemical modifications that influence structure and their biological activity (Tavormina et al. 2015). For example, the CLAVATA3/EMBRYO SURROUNDING REGION (CLE) and C-TERMINALLY ENCODED PEPTIDE (CEP) families have hydroxyprolines that are glycosylated with L-arabinose (Mohd-Radzman et al. 2015; Ohyama et al. 2008; Shinohara and Matsubayashi 2013; Xu et al. 2015). Of the total number of PCPs identified in each dataset, 19 to $33 \%$ contained posttranslational modifications or amino acid substitutions, as found by the PEAKS post-translational modification (PTM) and PEAKS Spider module, which are extensions of the de novo-assisted database searches (Supplementary Fig. S2). With the PEAKs software considering 313 natural modifications reported in the Unimod database, we observed PTMs that are likely introduced during sample preparation as well as those that are presumed to occur in vivo and have biological significance, like methylation and phosphorylation (Supplementary Fig. S3).
In the context of sample sets, PCPs matched to a maximum number of 522 proteins (Lb EXM samples) and a minimum number of 87 proteins (xylem sap samples) in the database (Fig. 3C, horizontal bars in UpSet plot). Like the peptide-level observation, we observed substantial overlap in the proteins detected in the Lb EXM, poplar roots with established ECM and poplar roots without ECM (Fig. 3C, horizontal bars in UpSet plot).

\section{De novo-assisted database searches enable the identification of nonfunctional and functional PCPs in the peptidome of different sample types.}

While the MS measurement by itself does not directly answer the question of what biological mechanisms are underpinning the presence or absence or relative amounts of a particular peptide, the observed peptide mapping patterns across the entire dataset provides some evidence to suggest whether the protein from which the peptides are observed is experiencing a selective or nonselective proteolytic cleavage process. That is,
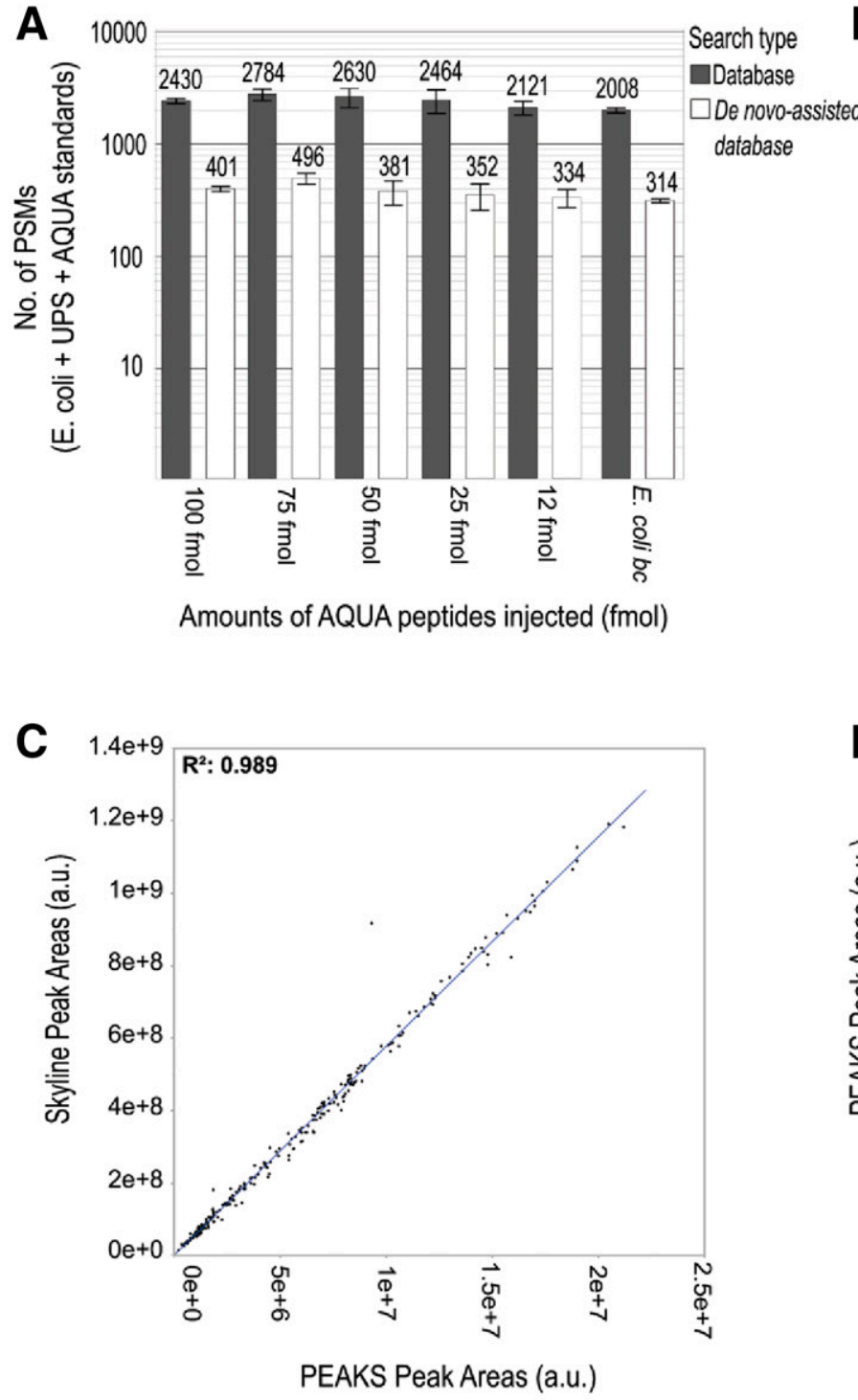

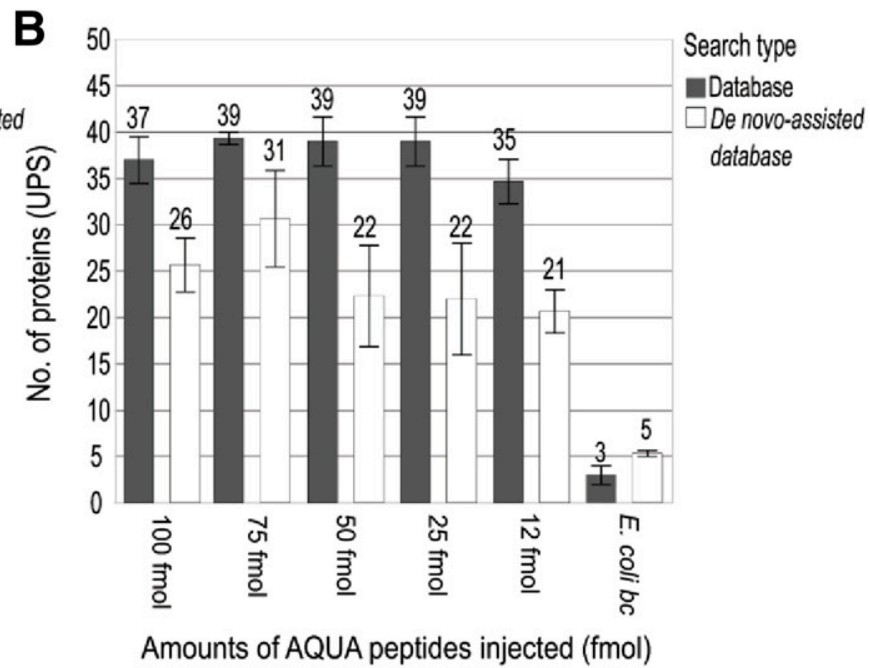

Fig. 2. Performance of 10-kDa membrane filtering and PEAKS software for peptide identification. For this study, we identified peptides from the universal proteomics standard (UPS) by de novo analysis and extracted quantitative information from the AQUA peptide standards spiked into Escherichia coli and UPS backgrounds after 10-kDa membrane filtering ( 15 samples $\times 17$ peptides $=255$ data points). A, The number of total identified peptide-spectrum matches (PSMs) for the benchmarking samples and B, the total number of identified UPS1 proteins are provided. C, Scatter plot of peptide peak areas reported by PEAKS compared with those identified by automatic and manual validation in Skyline. D, AQUA peptide standards linear responses based on PEAKs areas under the curve. Correlation coefficients $\left(R^{2}\right)$ are shown in each graph. 
proteins with random, spurious peptide-mapping peptides are more likely a product of protein degradation or turnover, whereas proteins with peptides mapping to a localized region or domain are likely the result of more precise posttranslational mechanisms.

PCPs derived from the action of proteolytic mechanisms during protein turnover and during protein maturation contribute to the total pool of native peptides in a cell. In plants, protein turnover is a fundamental component in plant development (Farrokhi et al. 2008; Nelson et al. 2014; Schaller 2004). As such, PCPs derived from the degradation of functional proteins can represent a significant fraction of a cell peptidome, but many of their functions are not well-understood (Fesenko et al. 2015). On the contrary, several families of bioactive PCPs in plants are derived from protein precursors during certain conditions, like in the presence of microbial pathogens or of heavy metals, and many of their functions have been characterized. Nevertheless, methodologies that can globally profile the expression of both types of PCPs directly in plant tissues and in their microbial partners are still lacking, and our experimental approach can potentially fill this void.

In our datasets, many PCPs mapped to housekeeping proteins like ribosomal subunits, elongation factors, and RuBisCO subunits (Supplementary Table S2). The role of these PCPs in ECM samples or samples without ECM were not further investigated or directly compared, but it is interesting to note that a recent study reported an increase of protein turnover in leaves of Populus $\times$ canescens plants inoculated in vitro with the ECM-forming fungi Paxillus involutus in comparison with control plants (Szuba et al. 2019). Similar observations have also been made for arbuscular mycorrhizal symbiotic systems grown in laboratories (Song et al. 2015; Takeda et al. 2009). Hence, our MS methodology in combination with others like traditional proteomics could be useful for more in-depth investigations on the plant proteolytic "degradome" (Farrokhi et al. 2008; Schaller 2004) by directly analyzing PCP abundance changes from plant tissues experiencing plant-microbial interactions compared with controls.
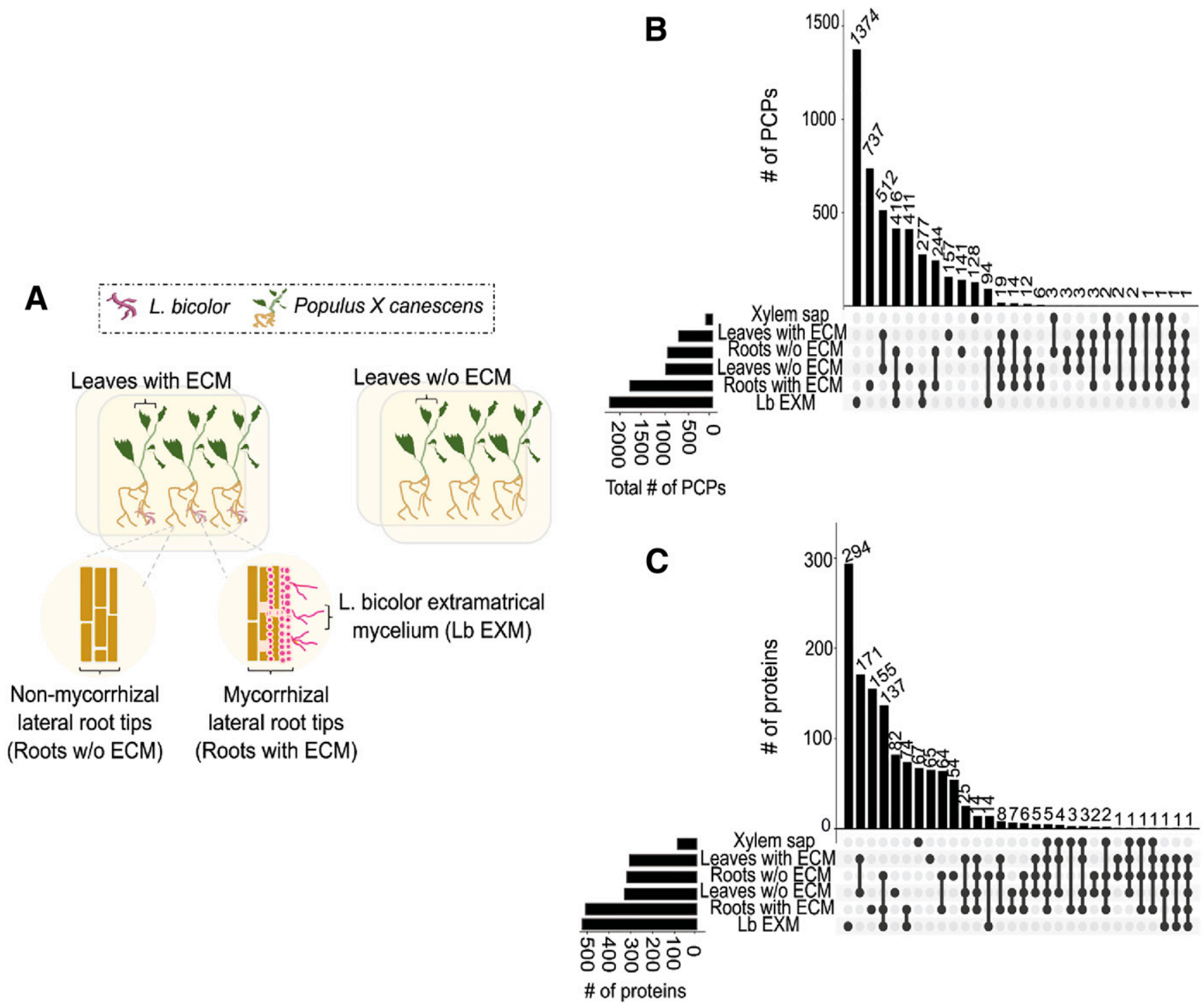

Fig. 3. Proteomics metrics of the Populus $\times$ canescens and Laccaria bicolor plant-microbe interaction system. A, Illustration of the sandwich-type system used to harvest different Populus $\times$ canescens extracts and L. bicolor extramatrical mycelium. Xylem sap was obtained from greenhouse-grown plants and is not shown in this figure. B, The UpSetR plot depicts the intersection between proteolytic cleavage products (PCPs) identified per experiment type. Horizontal bars indicate the total number of PCPs detected in each experiment (unique + shared); vertical bars depict the number of jointly identified PCPs. C, The UpSetR plot depicts the intersection between proteins to which PCPs mapped per experiment type. Horizontal bars indicate the total number of proteins detected in each experiment; vertical bars depict the number of jointly identified proteins. 
Apart from detecting members of the degradome, our approach was able to capture previously reported endogenous mechanisms of protein maturation that yielded nonfunctional or functional PCPs. For example, we were able to identify remnant nonfunctional PCPs that mapped to the $\mathrm{N}$ - and $\mathrm{C}$-terminus regions of histone H2BK4 of L. bicolor, suggesting a histone clipping mechanism (Fig. 4A) (Dhaenens et al. 2015; Yi and Kim 2018), as well as PCPs in Populus leaves representing the mature bioactive form of the precursor protein PsbTn, which is the smallest subunit of the photosystem II complex (Fig. 4B) (Shi and Schröder 2004). In addition, we observed uncharacterized PCPs that map exclusively to a particular protein domain or are localized to the $\mathrm{N}$ - or $\mathrm{C}$-terminus of a protein. For instance, PCPs mapping exclusively to a cysteine-rich domain (CFEM) common to a group of fungal extracellular membrane proteins (Kulkarni et al. 2003) (Fig. 4C) is a yet to be characterized process and it is plausible this provides evidence for a new post-translational mechanism of protein maturation that occurs at the plant microbe interface.

Of note, we were not able to identify representatives of known peptide families like CLEs, CEPs, or the RAPID ALKALINIZATION FACTOR peptides. Although these have been observed before in studies analyzing the peptidome of Medicago truncatula
(Mohd-Radzman et al. 2015; Patel et al. 2018), we suspect that the abundance of these PCPs in the tissues of Populus $\times$ canescens were beyond detection limits. In fact, RNA sequencing data collected for these samples measured these families at relatively low transcript abundance levels (data not shown).

\section{Comparative quantitative analysis of PCPs defines a set of significant analytes in ectomycorrhizal symbiosis between Populus $\times$ canescens and L. bicolor.}

A differential expression analysis of PCPs and the proteins they mapped to in root samples with or without ECM and Lb EXM was useful to narrow the dataset into groups of analytes with biological significance in the symbiotic associations between plant and fungus. Overall, 398 PCPs were differentially abundant (amalysis of variance [ANOVA] $P$ value $<0.05$ ) between roots with and without established ECM and Lb EXM. To further delineate the relevancy of PCPs to L. bicolor symbiosis with Populus roots, a Tukey honest significant difference posthoc test was performed to quantify abundance differences between relevant sample groups. Based on this analysis, a total of 157 PCPs were determined to be significant in the mutualistic interactions between Populus $\times$ canescens and L. bicolor
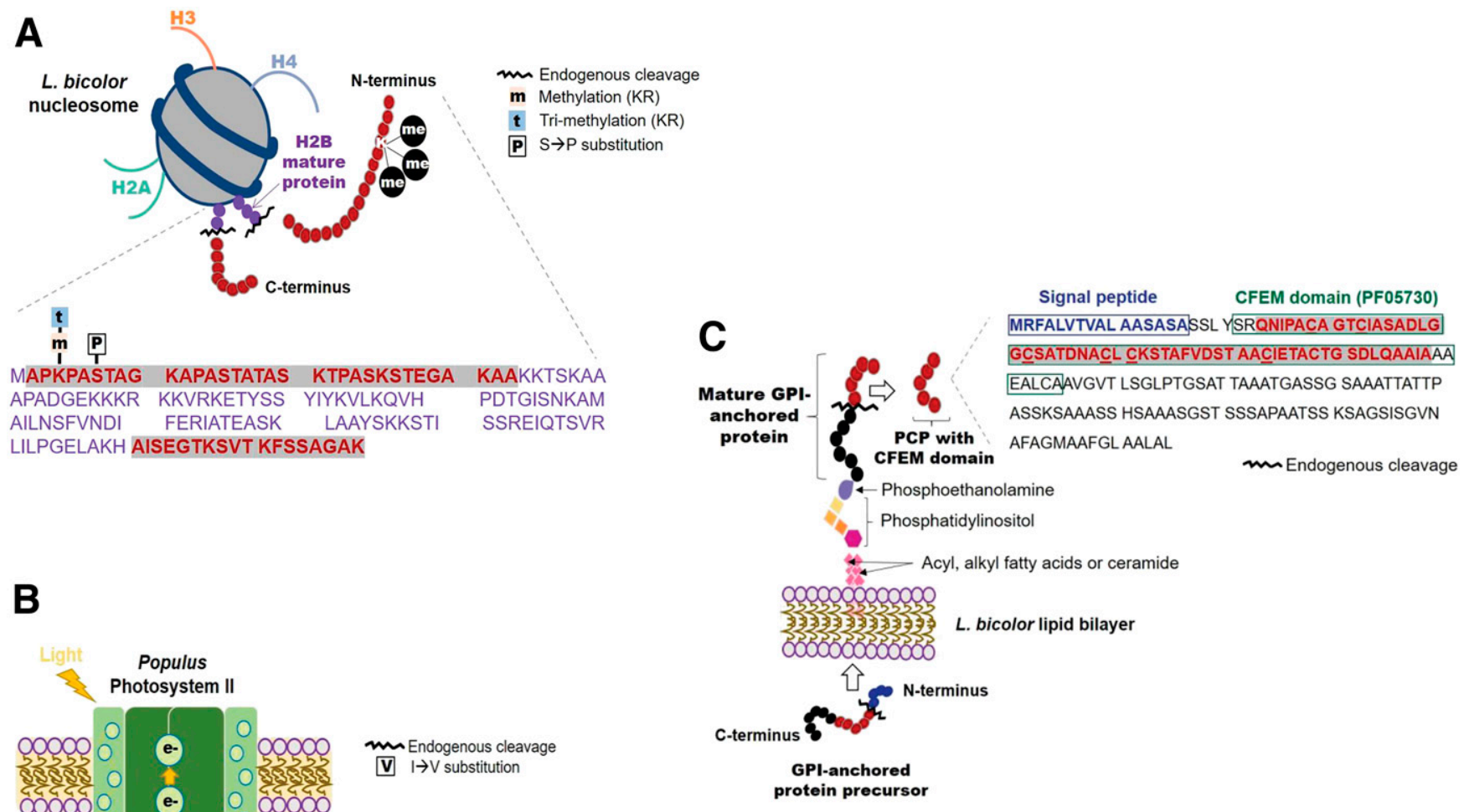

B

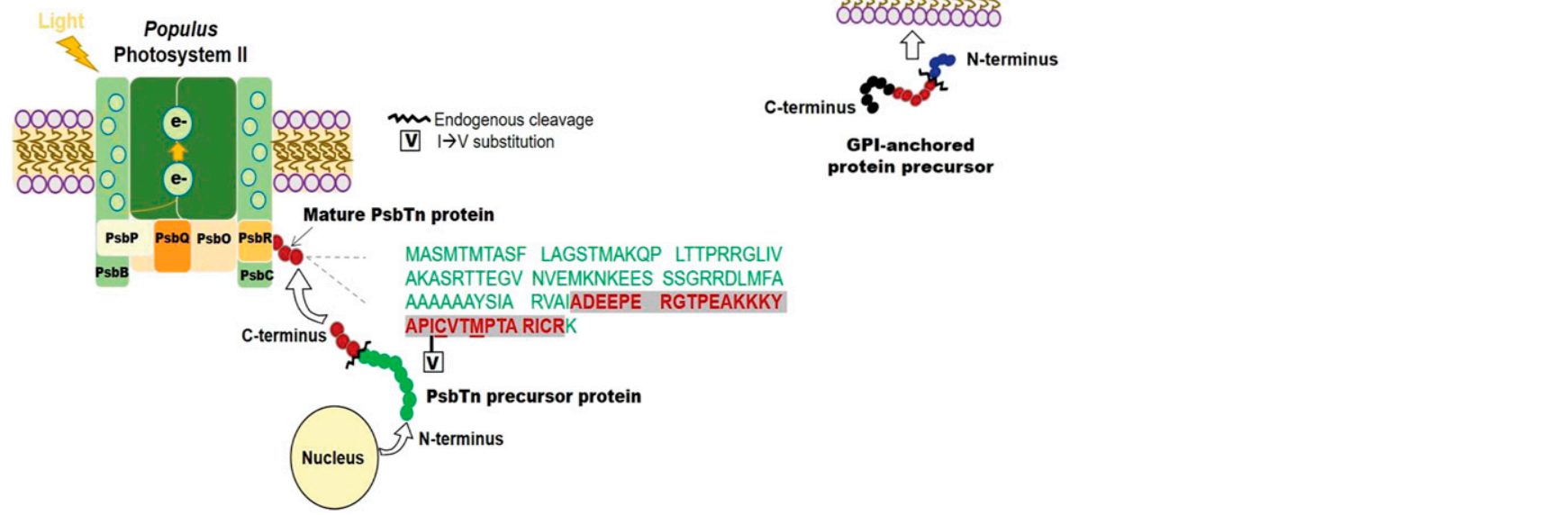

Fig. 4. Visual representations of detected proteolytic cleavage products (PCPs) (highlighted in gray and in red letters) produced as results of known and hypothesized protein maturation mechanisms in Populus and L. bicolor samples. A, PCPs mapped to the N-terminus and C-terminus regions of L. bicolor histone H2BK4 in L. bicolor extramatrical mycelium (Lb EXM) as well as root with and without established ectomycorrhiza (ECM). B, The mature form of protein PsbTn from the photosystem II complex of Populus spp. was identified in leaves with and without ECM. C, Identified PCPs from a cysteine-rich domain (CFEM)-containing protein with a predicted glycosylphosphatidylinositol (GPI)-anchored site. PCPs spanned most of the CFEM domain. Peptide mapping data are from Lb EXM. 
(Supplementary Table S3). Of the 157 PCPs, 96 mapped to 69 L. bicolor proteins, 56 mapped to 64 Populus proteins, and five were shared between 12 Populus and six L. bicolor proteins, respectively.

Similar to other large-scale 'omic' analyses, measured differences between relative abundances of analytes can be explained by numerous phenomena. Regarding PCPs, quantitative differences can arise from several levels of regulation (e.g., the amount of protein expression, the rate of protein translation, protein and peptide turnover rates, posttranslational modifications) and therefore, while we highlight several intriguing observations below and their likely implications, the one or more mechanisms regulating these differences are still largely unknown.

\section{L. bicolor endogenous PCPs associated with symbiosis with Populus $\times$ canescens.}

Among the differentially abundant $L$. bicolor PCPs in root with established ECM compared with Lb EXM were those belonging to a variant of the cysteine-rich C-terminus of the $L$. bicolor mycorrhiza-induced small secreted protein MiSSP7.6 (JGIv2 ID number 617208) that, in our database, is annotated as MiSSP7.7 and has $97.3 \%$ identity to MiSPP7.6. SignalP-5.0 (Almagro Armenteros et al. 2019) and Phobius (Käll et al. 2007) webservers agreed on the presence of a signal peptide on the first 21 amino acid residues of MiSSP7.7. It has been recently reported that MiSSP7.6 is secreted by L. bicolor and later imported into Populus cells as a mature PCP of 54 amino acids. The matured MiSSP7.6 localizes in the nuclei of plant root cells in which it interacts with two zinc-finger transcription factors belonging to the Myb/SANT-like DNA-binding domain protein family (Kang et al. 2020). The C-terminal PCPs detected in this study may point to a plausible mechanism of protein maturation. In addition, we identified PCPs that mapped to four putative small secreted proteins of $<250$ amino acids (Uniprot accessions B0DF3, B0D9T2, B0DP29, and B0DXP4) lacking functional annotation. As research on the symbiosis between Populus $\times$ canescens and L. bicolor has been uncovering novel small secreted proteins derived from both organisms that are necessary for the establishment and regulation of the symbiotic association of $L$. bicolor and poplar (Pellegrin et al. 2019; Plett et al. 2011, 2017; Vincent et al. 2012), this dataset contributes additional novel protein candidates associated with ectomycorrhizal symbiosis.

Another group of PCPs significantly higher in roots during the mutualistic interactions were found to map to several $L$. bicolor proteins involved in the detoxification of reactive oxygen species (ROS). This observation is likely related to the type of stress responses that ectomycorrhizal fungi can induce during root colonization, which include the generation of ROS species such as hydrogen peroxide, superoxide anion, and hydroxyl radicals (Johansson et al. 2004). Among those proteins, we identified a tyrosinase (B0DMA1) that provides resistance against ROS and phenolic compounds during early symbiosis (Piñero et al. 2007), a cysteine peroxiredoxin (B0CY32), and a manganese peroxidase (B0DVT9).

Among the differently expressed PCPs identified in L. bicolor, we also identified sequences that mapped to a lectin-related tectonin 1 protein (BOD1K0). In general, fungal lectins are best known to be part of the defense mechanisms against soil microbes and predators that act by targeting glycoepitopes in the cell surfaces of the latter (Sommer et al. 2018; Wohlschlager et al. 2014). However, fungal lectins that recognize host cell glycans in ECM, albeit not specifically in Populus-L. bicolor ECM, have also been hypothesized to help mediate the adhesion of partners to hosts (Giollant et al. 1993).
Interestingly, a study investigating the molecular mechanisms behind the physical interactions of L. bicolor S238N hyphae and its mycorrhiza-helper bacteria Pseudomonas fluorescens BBc6R found upregulation of the L. bicolor tectonin 2 gene, where it was suggested to have a role in cell-to-cell recognition (Deveau et al. 2007). Thus, it is plausible that the tectonin 1 found here has a similar function to tectonin 2 but with poplar root cells instead, which opens an interesting experimental opportunity for its functional validation.

\section{Populus $\times$ canescens endogenous PCPs associated with symbiosis with $L$. bicolor.}

Overall, the majority of the 56 Populus PCPs found to be significantly induced in ectomycorrhizal roots compared with nonmycorrhizal roots mapped to proteins related to stressresponse mechanisms, with the metallothionein (MT) protein family being highly represented. During endomycorrhizal symbiosis, MT proteins are generally hypothesized to provide protection against oxidative stress, including that caused by heavy metals (Lanfranco et al. 2002; Reddy et al. 2014). Interestingly, the differentially abundant PCPs map exclusively to the N-terminus and C-terminus of these proteins, which are both cysteine-rich regions. An intriguing explanation for the specific mapping to these regions is that Populus MTs experience posttranslational cleavage, a largely overlooked regulatory mechanism for this protein family. Cleavage of MT by proteases has been shown to be largely dependent on the loading of the protein with heavy metals (Klaassen et al. 1994) and occurs among the large stretch of amino acid residues separating the cysteine-rich domains (Hensbergen et al. 2001). A study on a plant MT expressed in E. coli showed that the linker region was sensitive to the bacterial proteolytic system (Kille et al. 1991); however, whether this process occurs in nature or its functional importance in symbiosis has not yet been shown.

Additionally, PCPs mapped to Populus housekeeping proteins that are involved in protein expression machinery (i.e., subunits of ribosomal proteins) or are components of active cell signaling/communication systems (i.e., ADP/ATP carrier proteins and metal transport proteins) or both. Similar observations have been reported at the transcript level in active ECM symbiosis between Pisolithus tinctorius and Eucalyptus globulus and between L. bicolor and P. trichocarpa, leading the authors to conclude that this was expected due to intense bilateral metabolic transfers and high assimilative activity (Voiblet et al. 2001). Of note, although we cannot accurately pinpoint specific mechanisms of how the PCPs observed from these proteins are being produced endogenously, there is no indication in literature that such molecules are further processed to mature bioactive PCPs and, thus, we can hypothesize that mechanisms of protein turnover or degradation are the most plausible explanations behind their identification by our experimental approach. Complementary proteomics analyses measuring the relative levels of protein precursors from which these PCPs are derived can confirm the natural degradation of these proteins or provide a different functional perspective from pools of PCPs or both, similar to what others have found previously (Fesenko et al. 2015).

\section{Differentially abundant PCPs shared between $L$. bicolor proteins and Populus $\times$ canescens proteins.}

The five differentially expressed and shared PCPs between Populus and L. bicolor mapped to functional domains of polyubiquitin and ubiquitin, which are well-conserved proteins across life (Morel et al. 2005). Ubiquitins can be found as monomers and polymers and have distinct roles in intracellular protein degradation via the proteasome pathway (Sultan et al. 2016; Zeppa et al. 2001). Several studies have demonstrated 
high and significant expression of ubiquitin genes in the establishment of ectomycorrhizal symbiotic associations. For example, in the Eucalyptus globulus-Pisolithus tinctorius ECM, upregulation of plant-derived transcripts encoding components of the ubiquitin pathway were reported, in which, it was hypothesized, these proteins help in mediating the downregulation of plant protein synthesis in colonizing roots (Voiblet et al. 2001). Another study analyzing the transcriptional responses in the ECM interaction between the basidiomycete Paxillus involutus and its host birch Betula pendula compared with extramatrical mycelium showed a polyubiquitin that was upregulated by 4.2-fold in ECM (Morel et al. 2005). In addition, the generation of ROS-like hydrogen peroxide is known to induce the expression of polyubiquitin in cells as a mechanism of detoxification (Johansson et al. 2004) and, in this study, we observed significant expression of fungi ROS-related enzymes in root with ECM.

\section{LC-MS/MS with de novo-assisted database searches is a viable strategy to identify novel PCPs in plant-microbe interfaces.}

Over the last couple of years, an increasing body of evidence at the transcript level has demonstrated the expression of bioactive PCPs in biotrophic plant-fungal associations. However, direct evidence of the products of genes and transcripts believed to be involved or participating in one or both ECM establishment and regulation is still lacking in literature but can certainly provide a new layer of evidence in the functional understanding of these molecules. As certain characteristics typical of endogenous PCPs in any biological system can make their identification laborious and difficult (i.e., unknown cleavage specificity, the presence of multiple PTMs, and relatively low natural abundances), experimental approaches that can comprehensively identify them with sensitivity and specificity are most welcome.

In this study, we systematically investigated the use of a $10-\mathrm{kDa}$ MWCO filtering strategy to enrich and quantify Populus and $L$. bicolor PCPs expressed in active mycorrhizal lateral root tips and identified novel peptide sequences using LC-MS/MS with a de novo-assisted database search strategy. Particularly, de novo-assisted database searches offer a way to detect functional products of genes and transcripts without biasing the identification toward the use of specific proteases or cleavage mechanisms, as in traditional large-scale protein studies.

The differential expression analysis of PCPs conducted throughout this study enumerated PCPs that have a role in the symbiotic interactions between both Populus and L. bicolor and provide theories of their biosynthetic origins. For example, we found evidence of L. bicolor PCPs mapping to the C-terminal region of a MiSSP7.6 protein and of PCPs that mapped to $\mathrm{N}$-terminus and C-terminus regions of Populus MT proteins that are related to stress responses happening during the formation of ECM. These cases highlighted the utility of the LC-MS/MS methodology to capture potential mechanisms of endogenous protein maturation. Interestingly, several PCPs mapped to small $L$. bicolor proteins of unknown function, from which four were predicted to be secreted.

Housekeeping proteins supporting crosstalk and metabolic adjustments between plant and fungi, such as transporters and ribosomal proteins, were also detected. It was hypothesized that the identification of PCPs and their PTMs mapping to these types of proteins are related to turnover/degradation proteolytic mechanisms, which are supposed to be upregulated in arbuscular mycorrhiza and ECM symbioses (Song et al. 2015; Szuba et al. 2019; Takeda et al. 2009). Their detection may prove useful alongside relative measurements of protein precursors to determine if such proteins are being subjected to natural turnover or if these PCPs serve another role in the symbiotic system under study.
Overall, this study provides experimental support for a quantitative strategy to investigate the global expression of PCPs in plantmicrobe interaction systems allowing to identify those with potential roles in their associations.

\section{MATERIALS AND METHODS}

\section{E. coli background proteome sample preparation.}

A crude $E$. coli proteome was prepared to provide a sample matrix for known target peptides for benchmarking. Briefly, an $E$. coli cell pellet (optical density $=0.4$ ) was suspended in lysis buffer ( $2 \%$ sodium deoxycholate [SDC] in $100 \mathrm{mM}$ $\mathrm{NH}_{4} \mathrm{HCO}_{3}[\mathrm{ABC}]$ ), was disrupted by sonication (30\% amplitude, $10 \mathrm{~s}$ pulse with $10 \mathrm{~s}$ rest, 2 min total pulse time), and was boiled for $5 \mathrm{~min}$. Crude protein extract was precleared via centrifugation in an Eppendorf Thermomixer for $15 \mathrm{~min}$ at $4,500 \times g$ and was quantified with a NanoDrop OneC spectrophotometer (Thermo Scientific). The precleared protein extract was then adjusted to $10 \mathrm{mM}$ dithiothreitol (DTT) and was incubated under constant shaking for $30 \mathrm{~min}$ at $37^{\circ} \mathrm{C}$ (600 rpm, Eppendorf Thermomixer) to avoid endogenous peptide cyclization or unwanted protein interactions. Cysteines were then blocked with $30 \mathrm{mM}$ iodoacetamide (IAM) to prevent reformation of disulfide bonds. The E. coli proteome sample was stored at $-20^{\circ} \mathrm{C}$ until further use.

\section{UPS1 sample preparation.}

One vial of UPS1 (Sigma) was solubilized in cell lysis buffer (2\% SDC in $100 \mathrm{mM} \mathrm{ABC)}$. Proteins were reduced with $10 \mathrm{mM}$ DTT and were incubated at $35^{\circ} \mathrm{C}$ under constant shaking for 30 min (600 rpm, Eppendorf Thermomixer). Afterward, proteins were alkylated with $30 \mathrm{mM}$ IAM, followed by a 15-min incubation at room temperature in the dark. The UPS1 sample was submitted to a 3-h trypsin digestion (1:20, enzyme to protein ratio) at room temperature under continuous shaking, followed by an overnight trypsin digestion using the same enzyme to protein ratio at $37^{\circ} \mathrm{C}$ under continuous shaking. The UPS1 tryptic digest was stored at $-20^{\circ} \mathrm{C}$ until further use.

\section{Heavy-labeled peptide standards.}

A total of 17 AQUA Ultimate-labeled ( $>97 \%$ purity) peptide standards (Thermo Scientific) were combined in a standard solution using $100 \mathrm{mM} \mathrm{ABC}$ as dilution buffer to individual concentrations of $10 \mathrm{fmol} / \mu \mathrm{l}$ (Supplementary Table S1). The AQUA mix was stored at $-20^{\circ} \mathrm{C}$ until further use.

\section{Preparation of master mixes \\ for bioinformatics pipeline demonstration.}

The master mix for benchmarking the identification of small peptides by the informatics pipeline was prepared on top of Vivaspin 500- $\mu$ l centrifugal filter units (MWCO $10 \mathrm{kDa}$, Millipore Sigma). To each filter, volumes equivalent to $100 \mu \mathrm{g}$ of $\mathrm{E}$. coli proteome and $0.24 \mu \mathrm{g}$ of digested UPS1, and volumes equivalent to $1,000,750,500,250$, and $125 \mathrm{fmol}$ of each standard in the AQUA mix were pipetted (experimental replicate per standard concentration $n=3$ ). Additionally, volumes equivalent to $100 \mu \mathrm{g}$ of $E$. coli proteome were also pipetted into three filters and used as background controls.

All samples were then centrifuged for $30 \mathrm{~min}$ at $12,000 \times g$ to remove proteins from the $E$. coli background proteome or undigested proteins from the UPS tryptic digest. The flowthrough was collected and acidified with $1 \%$ formic acid to precipitate SDC. Hydrated ethyl acetate was added to each sample at a 1:1 ( vol/vol) ratio three times to effectively remove SDC. Samples were then placed in a SpeedVac Concentrator (Thermo Fischer Scientific) to remove ethyl acetate. The peptide-enriched flow-throughs were desalted on a Pierce peptide desalting spin 
column (Thermo Scientific) per the manufacturer instructions. After speed-vac concentration, dry peptide samples were suspended in $10 \mu \mathrm{l}$ of $0.1 \%$ formic acid solution and were placed in autosampler vials.

\section{One-dimensional (1D)-LC-MS/MS \\ of master mixes samples.}

A Proxeon EASY-nLC 1200 system (Thermo Fisher Scientific) interfaced with a Q Exactive Plus (Thermo Fisher Scientific) mass spectrometer equipped with a nano-electrospray source were used to conduct 1D-LC-MS/MS analyses. Injection volumes of $2 \mu \mathrm{l}$ of each master mix $(n=15)$ were loaded in mobile phase A $(0.1 \%$ formic acid, $2 \%$ acetonitrile) onto a trap column $(150 \mathrm{~mm} \times$ $100 \mu \mathrm{m}$ ID) packed in-house with approximately $10 \mathrm{~cm}$ of $1.7 \mu \mathrm{m}$ Kinetex $\mathrm{C}_{18}$ resin (Phenomenex). Peptide separation was performed on an analytical column $(300 \mathrm{~mm} \times 75 \mu \mathrm{m}$ ID) packed in-house with $1.7-\mu \mathrm{m}$ particle size Kinetex $\mathrm{C}_{18}$ resin, using a linear gradient from 2 to $22 \%$ of mobile phase $\mathrm{B}(0.1 \%$ formic acid, $80 \%$ acetonitrile) at a flow rate of 300 nanoliters per minute over $90 \mathrm{~min}$.

Mass spectra were acquired with the Q Exactive Plus instrument in a top 10 data-dependent acquisition setup. MS spectra were collected within 300 to $1,500 \mathrm{~m} / \mathrm{z}$, with automatic gain control (AGC) target value of $3 \times 10^{6}$ at a resolution of 70,000 with a maximum injection time (IT) of $25 \mathrm{~ms}$. Precursor ions with charge states $\geq 2$ and $\leq 5$ and intensity threshold of $1.6 \times 10^{5}$ were isolated using a $1.6 \mathrm{~m} / \mathrm{z}$ isolation width for higher-energy C-trap collision dissociation (HCD) with a normalized collision energy of $27 \mathrm{eV}$. MS/MS spectra were acquired at a resolution of 17,500 at $\mathrm{m} / \mathrm{z}, 200$ with an AGC target value of $1 \times 10^{5}$ and maximum IT of $50 \mathrm{~ms}$. Dynamic exclusion was set to $20 \mathrm{~s}$ to avoid repeated sequencing of peptides. All spectral data collected in this study was deposited at the ProteomeXchange Consortium (number PXD015895) via the MassIVE repository (project identifier MSV000084471).

\section{Preparation of Populus $\times$ canescens and \\ L. bicolor samples: Poplar leaves, poplar sap, ectomycorrhizal roots, nonmycorrhizal roots, leaves, and extramatrical mycelium.}

The hybrid Populus $\times$ canescens $($ Populus tremula $\times$ Populus alba line INRA 717-1-B4) clones were micropropagated in vitro and were grown in half-strength Murashige and Skoog medium in a growth chamber at $24^{\circ} \mathrm{C}$ under a $16-\mathrm{h}$ photoperiod. The dikaryotic vegetative mycelia of strain $\mathrm{S} 238 \mathrm{~N}$ of the ectomycorrhizal fungus L. bicolor were maintained on modified Pachlewski agar medium P5 at $25^{\circ} \mathrm{C}$ in the dark (Deveau et al. 2007).

For in vitro coculture of poplar with L. bicolor, we used a sandwich system described before (Felten et al. 2009). The Petri dishes were incubated, for 2 weeks, vertically in a growth chamber at $20^{\circ} \mathrm{C}$ under a $16-\mathrm{h}$ photoperiod. From these coculture plates, we collected extramatrical mycelia (hyphae attached to and growing in the vicinity $[>1 \mathrm{~cm}]$ of the ectomycorrhizal roots), ectomycorrhizal lateral roots, nonmycorrhizal lateral roots, and leaves. Leaves from control plants (no ECM fungi) were harvested from plants grown separately but in the same in vitro conditions.

Cuttings of Populus $\times$ canescens (synonymous $P$. tremula $\times$ $P$. alba; INRA clone 717-1B4) of $1 \mathrm{~cm}$ diameter and $15 \mathrm{~cm}$ were planted in pots containing 5 liters of sterile sand and were grown in a greenhouse, irrigated twice a day with $20 \mathrm{ml}$ of nutrient solution $\left(8 \mu \mathrm{M} \mathrm{KNO} \mathrm{KN}_{3}, 8 \mu \mathrm{M} \mathrm{Ca}\left(\mathrm{NO}_{3}\right)_{2} \cdot 4 \mathrm{H}_{2} \mathrm{O}, 3\right.$ $\mu \mathrm{M} \mathrm{NaH}{ }_{2} \mathrm{PO}_{4}, 3 \mu \mathrm{M} \mathrm{MgSO}_{4} \cdot 7 \mathrm{H}_{2} \mathrm{O}, 0.2 \mu \mathrm{l}$ of Kanietra solution per liter (COFAZ). Xylem sap was extracted by natural root pressure after 7 weeks of growth as described previously (Kasper et al. 2021). To ensure xylem sap flow, poplars were watered with the nutrient solution $2 \mathrm{~h}$ before sap collection. Using a razor blade, poplars were then decapitated by transversal section of their stem $3 \mathrm{~cm}$ above its branching point from the cutting. To avoid contamination of the sap by other tissues of the stem, the cell layers surrounding the stele were removed with care around the section site with a scalpel on a surface $1 \mathrm{~cm}$ in length. After cleaning with deionized water and drying with tissues, the exposed stele was attached tightly to $3 \mathrm{~cm}$ of Tygon ND 100-65 tubes (Saint-Gobain Performance Plastics) of appropriate inner diameter with microporous tape (Urgo). Flowing xylem sap was collected regularly with a micropipette from the Tygon tubes. Samples were stored on ice during sampling. Sap $(150 \mu l$ per poplar) was collected over $3 \mathrm{~h}$ from 16 poplars. The sap from four poplars was pooled to produce one sample before flashfreezing the samples in liquid nitrogen.

\section{PCP extraction from Populus $\times$ canescens and L. bicolor samples.}

All samples derived from the ectomycorrhizal interactions of Populus $\times$ canescens with $L$. bicolor and from poplar alone were processed to recover endogenous polypeptides for LCMS/MS analysis. In an effort to minimize sample preparation-induced protein degradation, we tested commercial protease inhibitor cocktail solutions and found these solutions to contain inhibitors at concentrations that overwhelmed the LC-MS/MS analysis and negatively impacted the detection of PCPs. Therefore, endogenous protease activity was minimized by carefully lysing Populus and L. bicolor matrices in boiling alkaline-detergent lysis solution (Arul et al. 2016; Sköld et al. 2007). The use of alkaline bicarbonate buffer is also expected to limit endogenous proteases, which have low pH optima (Gundry et al. 2009). Briefly, ground samples were placed in $1 \mathrm{ml}$ of lysis buffer (2\% SDC in $100 \mathrm{mM} \mathrm{ABC})$, were vortexed, and then, were placed in a heat-block for $5 \mathrm{~min}$ at $90^{\circ} \mathrm{C}$. Afterward, samples were disrupted by ultrasonication and were boiled for an additional $5 \mathrm{~min}$ at $90^{\circ} \mathrm{C}$. When employing ultrasonication, shear forces generated during this process have the potential to break intramolecular protein bonds. To address this, we carefully controlled both the power input and cycling (program: $30 \%$ amplitude, $10 \mathrm{~s}$ pulse with $10 \mathrm{~s}$ rest, 2 min total pulse time) of the ultrasonication method (Chandrapala et al. 2011; Hansen et al. 2009).

After recovering the supernatant via centrifugation, the samples were adjusted to $10 \mathrm{mM}$ DTT and were incubated under constant shaking for $30 \mathrm{~min}$ at $37^{\circ} \mathrm{C}$ (600 rpm, Eppendorf Thermomixer). Cysteines were then blocked with $30 \mathrm{mM}$ IAM to prevent reformation of disulfide bonds. To separate the low-molecular weight fraction of the proteome, samples were transferred into $10-\mathrm{kDa}$ MWCO centrifugal filter units and were then centrifuged for $30 \mathrm{~min}$ at $12,000 \times \mathrm{g}$. The peptide-enriched flow-throughs were collected into fresh Eppendorf tubes and were acidified with $1 \%$ formic acid, to precipitate residual SDC. Samples were then placed in a SpeedVac Concentrator (Thermo Fischer Scientific) to remove ethyl acetate. Peptide samples were desalted on a Pierce peptide desalting spin column (Thermo Scientific) per the manufacturer instructions. After speed-vac concentration, dry samples were suspended in $10 \mu \mathrm{l}$ of $0.1 \%$ formic acid solution and were placed in autosampler vials.

\section{D-LC-MS/MS of Populus $\times$ canescens and \\ L. bicolor samples.}

All samples were analyzed on a Q Exactive Plus mass spectrometer (Thermo Fischer Scientific) coupled with a Proxeon EASY-nLC 1200 LC pump (Thermo Fisher Scientific). Peptides were separated on a $75-\mu \mathrm{m}$ inner diameter microcapillary column packed with $50 \mathrm{~cm}$ of Kinetex $\mathrm{C} 18$ resin $(1.7 \mu \mathrm{m}, 100 \AA$, 
Phenomenex) that was heated to $60^{\circ} \mathrm{C}$ in a Phoenix S\&T NanoLC column heater. For each sample, a 2- $\mu \mathrm{g}$ aliquot of recovered PCPs was loaded in buffer A ( $0.1 \%$ formic acid, $2 \%$ acetonitrile) and was eluted with a linear 90 -min gradient of 2 to $20 \%$ of buffer B ( $0.1 \%$ formic acid, $80 \%$ acetonitrile), followed by an increase in buffer B to $30 \%$ for $10 \mathrm{~min}$, another increase to $50 \%$ buffer for 10 min, and concluding with a 10 -min wash at $98 \%$ buffer A. The flow rate was kept at $200 \mathrm{nl} / \mathrm{min}$. MS data were acquired with the Thermo Xcalibur software version 4.27.19, using the topN method, in which $\mathrm{N}$ could be up to 10 . Target values for the full-scan MS spectra were $1 \times 10^{6}$ charges in the 300 to $1,500 \mathrm{~m} / \mathrm{z}$ range, with a maximum injection time of $25 \mathrm{~ms}$. Transient times corresponding to a resolution of 70,000 at $\mathrm{m} / \mathrm{z}, 200$ were chosen. A $1.6 \mathrm{~m} / \mathrm{z}$, isolation window and fragmentation of precursor ions was performed by HCD with a normalized collision energy of 30 . MS/MS scans were performed at a resolution of 17,500 at $\mathrm{m} / z 200$ with an ion target value of $1 \times 10^{6}$ and a maximum injection time of $50 \mathrm{~ms}$. Dynamic exclusion was set to $20 \mathrm{~s}$ to avoid repeated sequencing of peptides.

\section{PSMs, peptide, and protein identifications by PEAKS.}

The raw data were interrogated by de novo-assisted database searching against the Populus trichocarpa v3 reference proteome coupled to the $L$. bicolor UniProt reference proteome (UP000001194) accompanied with common contaminant proteins using PEAKS DB, PEAKS PTM, and PEAKS SPIDER in PEAKS $X$ Studio (Bioinformatics Solutions). The peptide and fragment ion mass tolerances were set to $\pm 10 \mathrm{ppm}$ and $\pm 0.02 \mathrm{Da}$, respectively. The enzyme parameter was set to "no enzyme". Features associated with chimera scan were enabled. De novo ALC score was set at $>90 \%$. A false discovery rate of $1 \%$ was applied to accept the peptide sequences and a minimum of three peptides were required to identify a protein. For PEAKS DB, carbamidomethylation $(+57.02)$ of cysteine was set as fixed modification and oxidation $(+15.99)$ of methionine was set as a variable modification. PEAKS PTM algorithm was used to identify other common modifications in PCPs by allowing the search against all possible modifications from the Unimod database. Similarly, PEAKS SPIDER algorithm was used to detect any possible de novo sequencing errors and homology peptide mutations.

For differential abundance analysis of PCPs involved in ECM interactions between Populus and L. bicolor, peptide data from the Populus roots with and without ECM as well as L. bicolor extramatrical mycelium sample sets were filtered to remove all peptides that were present in only one third of the replicates. All peptides present in two thirds of the biological replicates were considered valid for quantitative analysis. Missing data were imputed by random numbers drawn from a normal distribution (width $=0.3$ and downshift $=2.8$, using Perseus software) (Tyanova et al. 2016). The resulting matrix was subjected to ANOVA followed by the posthoc Tukey test to assess peptide abundance differences between the different experimental groups. The entire filtering and statistical analyses were done using an in-house developed Python script.

\section{AUTHOR-RECOMMENDED INTERNET RESOURCES}

MassIVE repository: https://massive.ucsd.edu/ProteoSAFe/static/massive.jsp Perseus software: http://maxquant.net/perseus

Proteome Exchange Consortium: http://www.proteomexchange.org

\section{LITERATURE CITED}

Almagro Armenteros, J. J., Tsirigos, K. D., Sønderby, C. K., Petersen, T. N., Winther, O., Brunak, S., von Heijne, G., and Nielsen, H. 2019. SignalP 5.0 improves signal peptide predictions using deep neural networks. Nat. Biotechnol. 37:420-423.
Amano, Y., Tsubouchi, H., Shinohara, H., Ogawa, M., and Matsubayashi, Y. 2007. Tyrosine-sulfated glycopeptide involved in cellular proliferation and expansion in Arabidopsis. Proc. Natl. Acad. Sci. U.S.A. 104: $18333-18338$.

Arul, A.-B., Han, N.-Y., Jang, Y.-S., Kim, H., Kim, H.-M., and Lee, H. 2016. Effects of heat shock treatment on enzymatic proteolysis for LCMS/MS quantitative proteome analysis. Mass Spectrom. Lett. 7:1-11.

Cassidy, L., Prasse, D., Linke, D., Schmitz, R. A., and Tholey, A. 2016. Combination of bottom-up 2D-LC-MS and semi-top-down GelFree-LCMS enhances coverage of proteome and low molecular weight short open reading frame encoded peptides of the archaeon Methanosarcina mazei. J. Proteome Res. 15:3773-3783.

Chandrapala, J., Zisu, B., Palmer, M., Kentish, S., and Ashokkumar, M. 2011. Effects of ultrasound on the thermal and structural characteristics of proteins in reconstituted whey protein concentrate. Ultrason. Sonochem. 18:951-957.

Chen, G. H., Huang, L. T., Yap, M. N., Lee, R. H., Huang, Y. J., Cheng, M. C., and Chen, S. C. 2002. Molecular characterization of a senescenceassociated gene encoding cysteine proteinase and its gene expression during leaf senescence in sweet potato. Plant Cell Physiol. 43:984-991.

Chen, Y. L., Fan, K. T., Hung, S. C., and Chen, Y. R. 2020. The role of peptides cleaved from protein precursors in eliciting plant stress reactions. New Phytol. 225:2267-2282.

Deveau, A., Palin, B., Delaruelle, C., Peter, M., Kohler, A., Pierrat, J. C., Sarniguet, A., Garbaye, J., Martin, F., and Frey-Klett, P. 2007. The mycorrhiza helper Pseudomonas fluorescens BBc6R8 has a specific priming effect on the growth, morphology and gene expression of the ectomycorrhizal fungus Laccaria bicolor S238N. New Phytol. 175 743-755.

Dhaenens, M., Glibert, P., Meert, P., Vossaert, L., and Deforce, D. 2015. Histone proteolysis: A proposal for categorization into 'clipping' and 'degradation'. BioEssays 37:70-79.

Dong, M., Ye, M., Cheng, K., Dong, J., Zhu, J., Qin, H., Bian, Y., and Zou, H. 2014. Identification of phosphopeptides with unknown cleavage specificity by a de novo sequencing assisted database search strategy. Proteomics 14:2410-2416.

Durgo, H., Klement, E., Hunyadi-Gulyas, E., Szucs, A., Kereszt, A., Medzihradszky, K. F., and Kondorosi, E. 2015. Identification of nodule-specific cysteine-rich plant peptides in endosymbiotic bacteria. Proteomics 15:2291-2295.

Farkas, A., Maróti, G., Durgő, H., Györgypál, Z., Lima, R. M., Medzihradszky, K. F., Kereszt, A., Mergaert, P., and Kondorosi, É. 2014. Medicago truncatula symbiotic peptide NCR247 contributes to bacteroid differentiation through multiple mechanisms. Proc. Natl Acad. Sci. U.S.A. 111:5183-5188.

Farrokhi, N., Whitelegge, J. P., and Brusslan, J. A. 2008. Plant peptides and peptidomics. Plant Biotechnol. J. 6:105-134.

Felten, J., Kohler, A., Morin, E., Bhalerao, R. P., Palme, K., Martin, F., Ditengou, F. A., and Legué, V. 2009. The ectomycorrhizal fungus Laccaria bicolor stimulates lateral root formation in poplar and Arabidopsis through auxin transport and signaling. Plant Physiol. 151: 1991-2005.

Fesenko, I. A., Arapidi, G. P., Skripnikov, A. Y., Alexeev, D. G., Kostryukova, E. S., Manolov, A. I., Altukhov, I. A., Khazigaleeva, R. A., Seredina, A. V., Kovalchuk, S. I., Ziganshin, R. H., Zgoda, V. G., Novikova, S. E., Semashko, T. A., Slizhikova, D. K., Ptushenko, V. V., Gorbachev, A. Y., Govorun, V. M., and Ivanov, V. T. 2015. Specific pools of endogenous peptides are present in gametophore, protonema, and protoplast cells of the moss Physcomitrella patens. BMC Plant Biol. 15:87.

Giollant, M., Guillot, J., Damez, M., Dusser, M., Didier, P., and Didier, E. 1993. Characterization of a lectin from Lactarius deterrimus (research on the possible involvement of the fungal lectin in recognition between mushroom and spruce during the early stages of mycorrhizae formation). Plant Physiol. 101:513-522.

Gundry, R. L., White, M. Y., Murray, C. I., Kane, L. A., Fu, Q., Stanley, B. A., and Van Eyk, J. E. 2009. Preparation of proteins and peptides for mass spectrometry analysis in a bottom-up proteomics workflow. Curr. Protoc. Mol. Biol. 90:10.25.1-10.25.23.

Hansen, K. C., Kiemele, L., Maller, O., O’Brien, J., Shankar, A., Fornetti, J., and Schedin, P. 2009. An in-solution ultrasonication-assisted digestion method for improved extracellular matrix proteome coverage. Mol. Cell. Proteomics 8:1648-1657.

Hensbergen, P. J., Donker, M. H., Hunziker, P. E., van der Schors, R. C., and van Straalen, N. M. 2001. Two metal-binding peptides from the insect Orchesella cincta (Collembola) as a result of metallothionein cleavage. Insect Biochem. Mol. Biol. 31:1105-1114.

Huffaker, R. C. 1990. Proteolytic activity during senescence of plants. New Phytol. 116:199-231. 
Jarnuczak, A. F., Lee, D. C., Lawless, C., Holman, S. W., Eyers, C. E., and Hubbard, S. J. 2016. Analysis of intrinsic peptide detectability via integrated label-free and SRM-based absolute quantitative proteomics. J. Proteome Res. 15:2945-2959.

Johansson, T., Le Quéré, A., Ahren, D., Söderström, B., Erlandsson, R., Lundeberg, J., Uhlén, M., and Tunlid, A. 2004. Transcriptional responses of Paxillus involutus and Betula pendula during formation of ectomycorrhizal root tissue. Mol. Plant-Microbe Interact 17:202-215.

Käll, L., Krogh, A., and Sonnhammer, E. L. 2007. Advantages of combined transmembrane topology and signal peptide prediction-The Phobius web server. Nucleic Acids Res. 35 (Web Server):W429-W432.

Kang, H., Chen, X., Kemppainen, M., Pardo, A. G., Veneault-Fourrey, C., Kohler, A., and Martin, F. M. 2020. The small secreted effector protein MiSSP7.6 of Laccaria bicolor is required for the establishment of ectomycorrhizal symbiosis. Environ. Microbiol. 22:1435-1446.

Kapp, E. A., Schütz, F., Connolly, L. M., Chakel, J. A., Meza, J. E., Miller, C. A., Fenyo, D., Eng, J. K., Adkins, J. N., Omenn, G. S., and Simpson, R. J. 2005. An evaluation, comparison, and accurate benchmarking of several publicly available MS/MS search algorithms: Sensitivity and specificity analysis. Proteomics 5:3475-3490.

Kasper, K., Abreu, I. N., Feussner, K., Zienkiewicz, K., Herrfurth, C., Ischebeck, T., Janz, D., Majcherczyk, A., Schmitt, K., Valerius, O., Braus, G. H., Feussner, I., Polle, A. 2021. Multi-omics analysis of xylem sap uncovers dynamic modulation of poplar defenses by ammonium and nitrate. bioRxiv 2021.05.28.446139.

Kawashima, Y., Fukutomi, T., Tomonaga, T., Takahashi, H., Nomura, F., Maeda, T., and Kodera, Y. 2010. High-yield peptide-extraction method for the discovery of subnanomolar biomarkers from small serum samples. J. Proteome Res. 9:1694-1705.

Kay, R., Barton, C., Ratcliffe, L., Matharoo-Ball, B., Brown, P., Roberts, J., Teale, P., and Creaser, C. 2008. Enrichment of low molecular weight serum proteins using acetonitrile precipitation for mass spectrometry based proteomic analysis. Rapid Commun. Mass Spectrom. 22:3255-3260.

Kille, P., Winge, D. R., Harwood, J. L., and Kay, J. 1991. A plant metallothionein produced in E. coli. FEBS Lett. 295:171-175.

Klaassen, C. D., Choudhuri, S., McKim, J. M., Jr., Lehman-McKeeman, L. D., and Kershaw, W. C. 1994. In vitro and in vivo studies on the degradation of metallothionein. Environ. Health Perspect. 102 (Suppl 3):141-146.

Kondo, T., Sawa, S., Kinoshita, A., Mizuno, S., Kakimoto, T., Fukuda, H., and Sakagami, Y. 2006. A plant peptide encoded by CLV3 identified by in situ MALDI-TOF MS analysis. Science 313:845-848.

Kulkarni, R. D., Kelkar, H. S., and Dean, R. A. 2003. An eight-cysteinecontaining CFEM domain unique to a group of fungal membrane proteins. Trends Biochem. Sci. 28:118-121.

Lanfranco, L., Bolchi, A., Ros, E. C., Ottonello, S., and Bonfante, P. 2002. Differential expression of a metallothionein gene during the presymbiotic versus the symbiotic phase of an arbuscular mycorrhizal fungus. Plant Physiol. 130:58-67.

Matsuzaki, Y., Ogawa-Ohnishi, M., Mori, A., and Matsubayashi, Y. 2010. Secreted peptide signals required for maintenance of root stem cell niche in Arabidopsis. Science 329:1065-1067.

Mergaert, P., Nikovics, K., Kelemen, Z., Maunoury, N., Vaubert, D., Kondorosi, A., and Kondorosi, E. 2003. A novel family in Medicago truncatula consisting of more than 300 nodule-specific genes coding for small, secreted polypeptides with conserved cysteine motifs. Plant Physiol. 132:161-173.

Mitchum, M. G., Wang, X., Wang, J., and Davis, E. L. 2012. Role of nematode peptides and other small molecules in plant parasitism. Annu. Rev. Phytopathol. 50:175-195.

Miyawaki, K., Tabata, R., and Sawa, S. 2013. Evolutionarily conserved CLE peptide signaling in plant development, symbiosis, and parasitism. Curr. Opin. Plant Biol. 16:598-606.

Mohd-Radzman, N. A., Binos, S., Truong, T. T., Imin, N., Mariani, M., and Djordjevic, M. A. 2015. Novel MtCEP1 peptides produced in vivo differentially regulate root development in Medicago truncatula. J. Exp. Bot. 66:5289-5300

Morel, M., Jacob, C., Kohler, A., Johansson, T., Martin, F., Chalot, M., and Brun, A. 2005. Identification of genes differentially expressed in extraradical mycelium and ectomycorrhizal roots during Paxillus involutus-Betula pendula ectomycorrhizal symbiosis. Appl. Environ. Microbiol. 71:382-391.

Müntz, K. 1996. Proteases and proteolytic cleavage of storage proteins in developing and germinating dicotyledonous seeds. J. Exp. Bot. 47:605-622.

Müntz, K., Belozersky, M. A., Dunaevsky, Y. E., Schlereth, A., and Tiedemann, J. 2001. Stored proteinases and the initiation of storage protein mobilization in seeds during germination and seedling growth. J. Exp. Bot. 52:1741-1752.
Muth, T., Hartkopf, F., Vaudel, M., and Renard, B. Y. 2018. A potential golden age to come-current tools, recent use cases, and future avenues for de novo sequencing in proteomics. Proteomics 18:1700150.

Narváez-Vásquez, J., Pearce, G., and Ryan, C. A. 2005. The plant cell wall matrix harbors a precursor of defense signaling peptides. Proc. Natl. Acad. Sci. U.S.A. 102:12974-12977.

Nelson, C. J., Alexova, R., Jacoby, R. P., and Millar, A. H. 2014. Proteins with high turnover rate in barley leaves estimated by proteome analysis combined with in planta isotope labeling. Plant Physiol. 166:91-108.

Ohyama, K., Ogawa, M., and Matsubayashi, Y. 2008. Identification of a biologically active, small, secreted peptide in Arabidopsis by in silico gene screening, followed by LC-MS-based structure analysis. Plant J. 55:152-160.

Ohyama, K., Shinohara, H., Ogawa-Ohnishi, M., and Matsubayashi, Y. 2009. A glycopeptide regulating stem cell fate in Arabidopsis thaliana. Nat. Chem. Biol. 5:578-580.

Patel, N., Mohd-Radzman, N. A., Corcilius, L., Crossett, B., Connolly, A., Cordwell, S. J., Ivanovici, A., Taylor, K., Williams, J., Binos, S., Mariani, M., Payne, R. J., and Djordjevic, M. A. 2018. Diverse peptide hormones affecting root growth identified in the Medicago truncatula secreted peptidome. Mol. Cell. Proteomics 17:160-174.

Pellegrin, C., Daguerre, Y., Ruytinx, J., Guinet, F., Kemppainen, M., Frey, N. F. D., Puech-Pagès, V., Hecker, A., Pardo, A. G., Martin, F. M., and Veneault-Fourrey, C. 2019. Laccaria bicolor MiSSP8 is a small-secreted protein decisive for the establishment of the ectomycorrhizal symbiosis. Environ. Microbiol. 21:3765-3779.

Piñero, S., Rivera, J., Romero, D., Cevallos, M. A., Martínez, A., Bolívar, F., and Gosset, G. 2007. Tyrosinase from Rhizobium etli is involved in nodulation efficiency and symbiosis-associated stress resistance. J. Mol. Microbiol. Biotechnol. 13:35-44.

Plett, J. M., Kemppainen, M., Kale, S. D., Kohler, A., Legué, V., Brun, A., Tyler, B. M., Pardo, A. G., and Martin, F. 2011. A secreted effector protein of Laccaria bicolor is required for symbiosis development. Curr. Biol. 21:1197-1203.

Plett, J. M., and Martin, F. M. 2018. Know your enemy, embrace your friend: Using omics to understand how plants respond differently to pathogenic and mutualistic microorganisms. Plant J. 93:729-746.

Plett, J. M., Yin, H., Mewalal, R., Hu, R., Li, T., Ranjan, P., Jawdy, S., De Paoli, H. C., Butler, G., Burch-Smith, T. M., Guo, H. B., Ju Chen, C., Kohler, A., Anderson, I. C., Labbé, J. L., Martin, F., Tuskan, G. A., and Yang, X. 2017. Populus trichocarpa encodes small, effector-like secreted proteins that are highly induced during mutualistic symbiosis. Sci. Rep. 7:382.

Reddy, M. S., Prasanna, L., Marmeisse, R., and Fraissinet-Tachet, L. 2014 Differential expression of metallothioneins in response to heavy metals and their involvement in metal tolerance in the symbiotic basidiomycete Laccaria bicolor. Microbiology 160:2235-2242.

Schaller, A. 2004. A cut above the rest: The regulatory function of plant proteases. Planta 220:183-197.

Schilling, B., Rardin, M. J., MacLean, B. X., Zawadzka, A. M., Frewen, B. E., Cusack, M. P., Sorensen, D. J., Bereman, M. S., Jing, E., Wu, C. C., Verdin, E., Kahn, C. R., Maccoss, M. J., and Gibson, B. W. 2012 Platform-independent and label-free quantitation of proteomic data using MS1 extracted ion chromatograms in skyline: Application to protein acetylation and phosphorylation. Mol. Cell. Proteomics 11:202-214.

Shi, L. X., and Schröder, W. P. 2004. The low molecular mass subunits of the photosynthetic supracomplex, photosystem II. Biochim. Biophys. Acta 1608:75-96.

Shinohara, H., and Matsubayashi, Y. 2013. Chemical synthesis of Arabidopsis CLV3 glycopeptide reveals the impact of hydroxyproline arabinosylation on peptide conformation and activity. Plant Cell Physiol 54:369-374.

Sköld, K., Svensson, M., Nilsson, A., Fälth, M., Svenningsson, P., and Andrén, P. 2007. The importance of sample handling in neuropeptidomics. In: Peptidomics. M., Soloviev C, Shaw, P. E.. Andren, eds. John Wiley \& Sons, Inc. New York.

Slavoff, S. A., Mitchell, A. J., Schwaid, A. G., Cabili, M. N., Ma, J., Levin, J. Z., Karger, A. D., Budnik, B. A., Rinn, J. L., and Saghatelian, A. 2013 Peptidomic discovery of short open reading frame-encoded peptides in human cells. Nat. Chem. Biol. 9:59-64.

Sommer, R., Makshakova, O.N., Wohlschlager, T., Hutin, S., Marsh, M. Titz, A., Kunzler, M., and Varrot, A. 2018. Crystal structures of fungal tectonin in complex with O-methylated glycans suggest key role in innate immune defense. Structure 26:391-402.

Song, F., Qi, D., Liu, X., Kong, X., Gao, Y., Zhou, Z., and Wu, Q. 2015. Proteomic analysis of symbiotic proteins of Glomus mosseae and Amorpha fruticosa. Sci. Rep. 5:18031.

Stec, B. 2006. Plant thionins-The structural perspective. Cell. Mol. Life Sci. 63:1370-1385 
Sultan, A., Andersen, B., Svensson, B., and Finnie, C. 2016. Exploring the plant-microbe interface by profiling the surface-associated proteins of barley grains. J. Proteome Res. 15:1151-1167.

Szuba, A., Marczak, Ł., Karliński, L., Mucha, J., and Tomaszewski, D. 2019. Regulation of the leaf proteome by inoculation of Populus $\times$ canescens with two Paxillus involutus isolates differing in root colonization rates. Mycorrhiza 29:503-517.

Takeda, N., Sato, S., Asamizu, E., Tabata, S., and Parniske, M. 2009. Apoplastic plant subtilases support arbuscular mycorrhiza development in Lotus japonicus. Plant J. 58:766-777.

Tavormina, P., De Coninck, B., Nikonorova, N., De Smet, I., and Cammue, B. P. 2015. The plant peptidome: An expanding repertoire of structural features and biological functions. Plant Cell 27:2095-2118.

Tyanova, S., Temu, T., Sinitcyn, P., Carlson, A., Hein, M. Y., Geiger, T., Mann, M., and Cox, J. 2016. The Perseus computational platform for comprehensive analysis of (prote)omics data. Nat. Methods 13:731-740.

Van de Velde, W., Zehirov, G., Szatmari, A., Debreczeny, M., Ishihara, H., Kevei, Z., Farkas, A., Mikulass, K., Nagy, A., Tiricz, H., Satiat-Jeunemaître, B., Alunni, B., Bourge, M., Kucho, K., Abe, M., Kereszt, A., Maroti, G., Uchiumi, T., Kondorosi, E., and Mergaert, P. 2010. Plant peptides govern terminal differentiation of bacteria in symbiosis. Science 327:1122-1126.

van Loon, L. C., Rep, M., and Pieterse, C. M. 2006. Significance of inducible defense-related proteins in infected plants. Annu. Rev. Phytopathol. 44:135-162.

Vincent, D., Kohler, A., Claverol, S., Solier, E., Joets, J., Gibon, J., Lebrun, M. H., Plomion, C., and Martin, F. 2012. Secretome of the free-living mycelium from the ectomycorrhizal basidiomycete Laccaria bicolor. J. Proteome Res. 11:157-171.

Voiblet, C., Duplessis, S., Encelot, N., and Martin, F. 2001. Identification of symbiosis-regulated genes in Eucalyptus globulus-Pisolithus tinctor- ius ectomycorrhiza by differential hybridization of arrayed cDNAs. Plant J. 25:181-191.

Whitford, R., Fernandez, A., Tejos, R., Pérez, A. C., Kleine-Vehn, J., Vanneste, S., Drozdzecki, A., Leitner, J., Abas, L., Aerts, M., Hoogewijs, K., Baster, P., De Groodt, R., Lin, Y. C., Storme, V., Van de Peer, Y., Beeckman, T., Madder, A., Devreese, B., Luschnig, C., Friml, J., and Hilson, P. 2012. GOLVEN secretory peptides regulate auxin carrier turnover during plant gravitropic responses. Dev. Cell 22: 678-685.

Wohlschlager, T., Butschi, A., Grassi, P., Sutov, G., Gauss, R., Hauck, D., Schmieder, S. S., Knobel, M., Titz, A., Dell, A., Haslam, S. M., Hengartner, M. O., Aebi, M., and Künzler, M. 2014. Methylated glycans as conserved targets of animal and fungal innate defense. Proc. Natl. Acad. Sci. U.S.A. 111:E2787-E2796.

Xu, T.-T., Ren, S.-C., Song, X.-F., and Liu, C.-M. 2015. CLE19 expressed in the embryo regulates both cotyledon establishment and endosperm development in Arabidopsis. J. Exp. Bot. 66:5217-5227.

Yi, S. J., and Kim, K. 2018. Histone tail cleavage as a novel epigenetic regulatory mechanism for gene expression. BMB Rep. 51:211-218.

Zeppa, S., Potenza, L., Polidori, E., Guescini, M., Agostini, D., Giomaro, G., and Stocchi, V. 2001. Cloning and characterisation of a polyubiquitin gene from the ectomycorrhizal fungus Tuber borchii vittad. Curr. Genet. 40:49-53.

Zhang, J., Xin, L., Shan, B., Chen, W., Xie, M., Yuen, D., Zhang, W., Zhang, Z., Lajoie, G.A., and Ma, B. 2012. PEAKS DB: De novo sequencing assisted database search for sensitive and accurate peptide identification. Mol. Cell Proteomics 11:M111 010587.

Zhang, K., McKinlay, C., Hocart, C. H., and Djordjevic, M. A. 2006. The Medicago truncatula small protein proteome and peptidome. J. Proteome Res. 5:3355-3367.

This article was modified on 9 Nov 2021. 


\section{ERRATUM / Volume 33, No. 10, 2020 / MPMI-04-20-0082-TA}

In the article "A Viable New Strategy for the Discovery of Peptide Proteolytic Cleavage Products in Plant-Microbe Interactions" by Manuel I. Villalobos Solis, Suresh Poudel, Clemence Bonnot, Him K. Shrestha, Robert L. Hettich, Claire Veneault-Fourrey, Francis Martin, and Paul E. Abraham, a reference for the sap extraction technique was not provided in the original text. This technique was adapted from the work of K. Kasper and A. Polle of the Goettingen Center for Molecular Biosciences at the University of Goettingen. Their original work can be found in bioRxiv under the title "Multi-omics analysis of xylem sap uncovers dynamic modulation of poplar defenses by ammonium and nitrate" by Kasper et al. (doi: https://doi.org/10.1101/2021.05.28.446139).

This manuscript has been authored by UT-Battelle, LLC under Contract No. DE-AC05-00OR22725 with the U.S. Department of Energy. The United States Government retains and the publisher, by accepting the article for publication, acknowledges that the United States Government retains a non-exclusive, paid-up, irrevocable, worldwide license to publish or reproduce the published form of this manuscript, or allow others to do so, for United States Government purposes. The Department of Energy will provide public access to these results of federally sponsored research in accordance with the DOE Public Access Plan. 